\title{
Metassíntese de pesquisas sobre conhecimentos/saberes na formação continuada de professores que ensinam matemática
}

\section{Research meta-synthesis on the knowledge in in-service teacher education of teachers who teach mathematics}

\author{
Dario Fiorentini ${ }^{1}$ \\ Vanessa Moreira Crecci ${ }^{2}$
}

\begin{abstract}
Resumo
Este artigo visa compreender o modo como as pesquisas brasileiras sobre formação continuada concebem e investigam os saberes e conhecimentos profissionais de professores que ensinam matemática e sua relação com as práticas profissionais. Após mapear os focos temáticos de estudo das teses de doutorado sobre formação continuada relativas ao Projeto de "Mapeamento e Estado da Arte da Pesquisa Brasileira sobre o Professor que Ensina Matemática", no período 2001-2012, foram encontradas 13 dentre elas que abordam os conhecimentos e saberes profissionais do professor que ensina matemática e que constituem o corpus da revisão sistemática deste estudo. Os resultados de uma metassíntese desse corpus apontam diferentes maneiras de conceber e desenvolver estes estudos e evidenciam contribuições, possibilidades e limites acerca da especificidade e da natureza dos saberes e conhecimentos profissionais de professores que ensinam matemática em um contexto de formação e aprendizagem docente em serviço.
\end{abstract}

Palavras-chave: Professor que ensina matemática; Saberes docentes; Conhecimentos profissionais; Metassíntese.

\begin{abstract}
This article aims to understand the way Brazilian researches on in-service teacher education conceive and investigate the professional knowledge of mathematics teachers and their relation to their professional practices. After mapping the thematic focuses of $\mathrm{PhD}$ theses on in-service teacher education concerning the project of "Mapping and State of the Art of Brazilian Research about teachers who teach Mathematics" between 2001 and 2012, 13 studies on the knowledge of teachers who teach mathematics were found and they constitute the corpus of the systematic review of this study. The results of this meta-synthesis point to different ways of conceiving and developing these studies and they highlight trends, contributions, possibilities and limits about the study of the specificity and nature of professional knowledge of teachers who teach mathematics in an education context and teaching learning in service.
\end{abstract}

Keywords: Teachers who teach mathematics; Teaching knowledge; Professional knowledge; Meta-synthesis.

\footnotetext{
1 Doutor em Educação pela Universidade Estadual de Campinas. Professor da Universidade Estadual de Campinas. Brasil. E-mail: dariof@unicamp.br.

2 Doutora em Educação pela Universidade Estadual de Campinas. Professora da Faculdade SESI-SP de Educação. Brasil. E-mail: vanessa.crecci@faculdadesesi.edu.br.
} 


\section{Introdução}

O presente estudo é parte de um projeto maior intitulado "Mapeamento e Estado da Arte da Pesquisa Brasileira sobre o Professor que Ensina Matemática (PEM)" que visa "mapear, descrever e sistematizar as pesquisas brasileiras - produzidas no âmbito dos programas de Pós-Graduação stricto sensu das áreas de Educação e Ensino da CAPES, no período de 2001 a 2012 - que têm como foco de estudo o PEM. Trata-se de um Projeto financiado pelo CNPq e coordenado pelo Grupo de Estudos e Pesquisas sobre Formação de Professores de Matemática (GEPFPM) ${ }^{3}$.

O objetivo deste artigo é compreender o modo como as pesquisas brasileiras sobre formação continuada concebem e investigam os saberes e conhecimentos profissionais de professores que ensinam matemática e sua relação com as práticas letivas. Iniciamos, descrevendo o percurso metodológico e o contexto deste estudo, destacando uma fase inicial de seleção e mapeamento de teses de doutoramento sobre formação continuada e, dentre elas, delimitar aquelas que atendem ao nosso objetivo, - isto é, que exploraram e investigam os conhecimentos e saberes profissionais do PEM - e que passarão por um processo de revisão sistemática na modalidade de metassíntese. E, após apresentar uma discussão prévia acerca dos saberes e conhecimentos profissionais do professor, desenvolvemos uma metassíntese desses trabalhos, produzindo, primeiramente, uma síntese interpretativa de cada trabalho, seguida de sínteses integrativas de três conjuntos de trabalhos afins. Concluímos com um balanço síntese, em que discutimos tendências e os principais resultados obtidos.

\section{Percurso metodológico e o contexto do estudo}

O referido projeto de 'Mapeamento e Estado da Arte da Pesquisa Brasileira sobre o PEM" teve início em 2013, tendo contado, em sua primeira fase, com a participação de sete equipes de diferentes regiões ou estados do Brasil, tendo, cada uma, a responsabilidade de localizar e mapear, em sua região, as pesquisas de mestrado e doutorado da Área de Educação e Ensino da Capes que tinham como foco de estudo o PEM. Ao final dessa fase, foram fichados e mapeados 858 teses e dissertações, sendo 96 dissertações de Mestrado profissional, 584 dissertações de Mestrado acadêmico e 178 teses de Doutorado.

Após fichar todos esses trabalhos, cada regional ou estado mapeou os aspectos físicos, as tendências metodológicas e os focos temáticos privilegiados pelas pesquisas. As categorias temáticas foram previamente definidas pela coordenação do projeto, baseando-se na literatura internacional sobre o professor e sua formação. Este mapeamento encontra-se disponível em Fiorentini, Passos e Lima (2016).

\footnotetext{
${ }^{3}$ Grupo interinstitucional, com sede na FE/Unicamp, que congrega pesquisadores de várias universidades: Unicamp; Unesp/Rio Claro; UFSCar; USF; PUC-Campinas; Unifei; UFSC; SESI-SP/Educação; UNIP.
} 
DOI: http://dx.doi.org/10.20396/zet.v25i1.8647773

Para a segunda fase de estudo do projeto, foi prevista a realização de uma revisão sistemática dos estudos nas modalidades estado arte da pesquisa, metanálise e metassíntese de partes específicas do corpus geral. Um dos subgrupos do Projeto, do qual os autores do presente trabalho fazem parte, interessado em compreender a configuração do PEM como campo de conhecimento e de pesquisa, decidiu realizar revisões sistemáticas das teses de doutorado, por presumir que elas poderiam trazer maior contribuição. Assim, tomando o conjunto de 178 teses de doutorado do corpus original, as teses foram dividas em quatro categorias: 63 estudos realizados no contexto da formação inicial (FI); 46 estudos no contexto da formação continuada (FC); 08 estudos no contexto da formação inicial e continuada (FIC); e 61 estudos sobre outros contextos e aspectos (OC). Para mapear tematicamente os 46 estudos de doutorado relativos à $\mathrm{FC}$, tomamos por base os 9 focos temáticos de estudo definidos previamente pelo Projeto, a distribuição quantitativa pode ser conferida no Quadro 01 .

Quadro 01 - Focos de estudo das teses sobre formação continuada do PEM

\begin{tabular}{|l|c|}
\hline \multicolumn{1}{|c|}{ Focos de estudo } & n \\
\hline Saberes e conhecimentos profissionais & 13 \\
\hline Aprendizagem docente e desenvolvimento profissional & 10 \\
\hline Cursos/programas/projetos/disci-plinas de formação docente & 08 \\
\hline Outros focos de estudo: práticas letivas ou profissionais do PEM & 07 \\
\hline Atitudes, crenças, concepções e representações do PEM & 04 \\
\hline Identidade e profissionalidade do PEM & 02 \\
\hline História do PEM e/ou de sua formação & 01 \\
\hline Formador de professores que ensinam Matemática & 01 \\
\hline Total & 46 \\
\hline
\end{tabular}

Fonte: Os autores deste artigo 
Tendo em vista o espaço limitado deste artigo e nosso propósito de compreender o modo como as pesquisas brasileiras concebem e investigam os saberes e conhecimentos do PEM, definimos como corpus para revisão sistemática, na modalidade metassíntese, os 13 trabalhos relativos ao foco "saberes e conhecimentos profissionais".

Fiorentini e Coelho (2012), ancorados sobretudo em Godfrey e Denby (2006), descrevem a metassíntese como sendo um processo que "consiste, primeiramente, na produção de evidências qualitativas (isto é, pequenas sínteses interpretativas) que são extraídas de cada pesquisa acerca de um problema, fenômeno ou foco de estudo para, a seguir, serem relacionadas (confrontadas ou contrastadas)" (p. 1.056), de modo a produzir uma nova síntese de interpretações, podendo ser, essa última, uma síntese integrativa ou problematizadora das sínteses anteriores.

Considerando que nosso corpus de análise/interpretação é constituído por pesquisas de natureza qualitativa e que trazem, como resultado, sínteses que resultaram de um processo de análise e interpretação sistemática de dados de primeira ordem (isto é, de dados empíricos de campo acerca dos saberes e conhecimentos profissionais sobre o ensino de matemática mobilizados por professores), pretendemos produzir um estudo de segunda ordem, isto é, elaborar, primeiro, sínteses interpretativas de cada trabalho e, a seguir, sínteses integrativas e compreensivas de conjuntos de trabalhos afins, destacando como as pesquisas brasileiras concebem, tratam e investigam os saberes e conhecimentos profissionais do PEM. É claro que esse processo de metassíntese é marcado pelo viés dos pesquisadores de segunda ordem, de modo que outros pesquisadores, com outros vieses, poderão produzir outras interpretações e compreensões sobre o fenômeno e os trabalhos aqui investigados.

\section{Discussão prévia sobre saberes e conhecimentos profissionais do professor}

Para orientar e embasar a revisão sistemática dos 13 trabalhos, consideramos pertinente fazer uma discussão prévia sobre a diferenciação entre saberes e conhecimentos da profissão docente, retomando alguns estudiosos dessa temática.

No final dos anos de 1990, Fiorentini, Souza Jr e Melo realizaram um ensaio teórico sobre a especificidade e a complexidade dos saberes docentes, considerando principalmente o modo como esses são mobilizados, elaborados/reelaborados e ressignificados no contexto da prática docente. Embora a diferenciação entre saberes e conhecimentos seja problemática, preferimos, no presente artigo, para efeito de metassíntese, manter a diferenciação estabelecida originalmente por Fiorentini et al. (1998), concebendo "o saber" como uma categoria ampla que engloba várias formas de saber fazer, ser e conhecer e que podem ser implícitas (inconscientes) ou explícitas (conscientes). Assumimos que, quando um saber, ou parte dele, passa ao nível de consciência, geralmente via análise ou sistematização, esse saber se torna também um "conhecimento". Ou seja, consideramos o conhecimento como uma forma especial de saber que se diferencia por ser consciente ou explícito, após passar por um processo de sistematização. 
Não queremos, com isso, afirmar que o conhecimento é uma categoria superior ao saber. Ambos têm relevância e fazem parte das práticas sociais humanas. Entretanto, o processo de pesquisa tem papel importante na transformação do saber em conhecimento. Mas que valor tem o conhecimento, se ele não estiver situado em uma prática social? Se ele não servir para compreender melhor o mundo e as práticas? Acreditamos, neste sentido, que o saber ser e fazer do professor transforma-se, não pela simples aplicação de conhecimentos, mas pela problematização das práticas de ensinar e aprender, tendo como referência conhecimentos oriundos de pesquisas.

Considerando o campo específico dos saberes e conhecimentos relativos à docência em matemática ou à formação de professores que ensinam matemática, os principais aportes teóricos utilizados pelos pesquisadores brasileiros, até os dez primeiros anos do século XXI, têm sido Shulman (1986, 1987), Tardif, Lessard e Lahaye (1991) e Gauthier e Tardif (1997).

Shulman (1986, 1987) notabilizou-se por destacar e defender conhecimentos profissionais específicos da docência ou do professor, e que vão além do (1) conhecimento do conteúdo ou do (2) conhecimento pedagógico geral, como é o caso do (3) conhecimento pedagógico do conteúdo, o qual distingue o professor de um especialista do conteúdo, pois contempla aspectos do conteúdo vinculados ao seu processo de ensino, incluindo modos ou estratégias de explorar as noções e os significados desse conteúdo específico, valendo-se do uso de exemplos, contraexemplos, ilustrações, analogias e estratégias que possam incrementar a aprendizagem dos estudantes. Além desses três, Shulman (1987) inclui mais quatro conhecimentos do professor: (4) do currículo (específico da matéria e de outras matérias conexas e compreendem os programas de ensino, os materiais didáticos, os softwares etc); (5) dos alunos; (6) dos contextos educativos e (7) dos fins e valores educativos.

Autores canadenses como Gauthier e Tardif (1997), entretanto, preferem utilizar o termo saber docente ao invés de conhecimento profissional do professor, pois tomam como principal referência o trabalho docente nas escolas. Para esses autores, é a atividade do trabalho docente, no qual são mobilizados e produzidos diversos saberes, que torna os professores em profissionais do ensino.

Sendo assim, parece não fazer sentido discutir e investigar os saberes dos professores de modo dissociado das práticas docentes e de quem as produz. Fiorentini (2000) entende que "o professor, sua prática e seus saberes formam uma tríade de entidades que 'interdependem' e 'copertencem' a uma situação e trabalho na qual 'coevoluem' e continuamente se transformam" [ênfase no original] (p. 187). Fiorentini, Nacarato e Pinto (1999), por outro lado, sintetizam, com base em Tardif e colaboradores (1991), que o saber docente é reflexivo, plural e complexo "porque histórico, provisório, contextual, afetivo, ético-político, cultural, formando uma teia, mais ou menos coerente e imbricada, de saberes científicos - oriundos das ciências da educação, dos saberes das disciplinas, dos currículos e de saberes da experiência e da tradição pedagógica" (p. 55). 
Mais recentemente, Ball, Thames e Phelps (2008), ao fazerem uma releitura dos estudos de Shulman, colocam no centro o conhecimento matemático e distinguem dois domínios básicos do conhecimento matemático do professor no contexto do ensino: conhecimento do conteúdo da matéria de ensino e conhecimento pedagógico do conteúdo. A principal contribuição desse estudo está na distinção de três subdomínios do "conhecimento do conteúdo da matéria de ensino", em que diferenciam o "conhecimento comum" de matemática (que todo o cidadão deveria saber) do "conhecimento especializado do conteúdo" (que todo o PEM deveria saber e que se diferencia do conhecimento matemático acadêmico ou de outras profissões) e do "conhecimento matemático no horizonte" (conhecimento extensivo da matemática, isto é, de outros tópicos do currículo escolar da matemática ou do campo do conhecimento matemático e que têm conexão ou relação com o que está sendo ensinado e aprendido num determinado momento). Outro domínio importante aos pesquisadores em educação matemática é o "conhecimento pedagógico do conteúdo", no qual são distinguidos três subdomínios: "conhecimento do conteúdo e dos alunos"; "conhecimento do conteúdo e do ensino"; e "conhecimento do conteúdo e do currículo".

Cochran-Smith e Lytle (1999), entretanto, diferenciam-se desses autores por centrarem foco não no conhecimento profissional em si, mas na sua relação com a prática docente, destacando três concepções de produção e aprendizagem de conhecimentos docentes. Essas concepções podem ser simplificadas a partir da função que elas teriam em relação ao trabalho do professor em sua prática de ensinar e aprender e que são assim expressas: produção/aprendizagem de conhecimentos PARA, NA e DA prática de ensinar e aprender. Embora essas concepções sejam conflitantes entre si e compitam de maneiras diferentes, as autoras nos alertam que elas coexistem, às vezes de maneira sutil, no mundo da política, da pesquisa e da prática educacional e são invocadas por pessoas de posições diferenciadas para explicar e justificar ideias completamente diversas sobre como alcançar a melhoria da formação do professor e, por decorrência, do ensino e da aprendizagem (Fiorentini, 2013).

$\mathrm{Na}$ primeira concepção - conhecimento/aprendizagem PARA a prática - os conhecimentos formais e as teorias são produzidos por pesquisadores acadêmicos PARA serem ensinados e aplicados na formação ou na prática escolar. Na segunda concepção conhecimento e aprendizagem NA prática - pressupõe-se que muitos dos conhecimentos essenciais para a prática de ensinar são de natureza prática e, portanto, são produzidos na própria prática, não podendo ser ensinados, mas evoluem com o tempo, tendo como principal referência os professores experientes e reflexivos. Na terceira concepção - conhecimento e aprendizagem DA prática - não há uma separação entre conhecimento prático e teórico. Presume-se que o conhecimento que os professores precisam para ensinar é produzido, quando eles tomam sua própria prática, como campo de investigação ou análise, e os conhecimentos produzidos por outros especialistas, como instrumento de interpretação e análise. 
Diante dessa discussão teórica, recolocamos a questão investigativa que orientará a metassíntese a ser desenvolvida a seguir: o que as teses de doutorado, defendidas entre 2001 e 2012, sobre formação continuada de professores que ensinam Matemática - e que tem como foco de estudo os saberes e conhecimentos profissionais - nos revelam acerca desses saberes e conhecimentos, sobretudo como eles têm sido investigados e sistematizados em contextos de formação continuada?

\section{Revisão e sínteses interpretativas e integrativas dos estudos}

Nesta seção, tentamos produzir uma síntese interpretativa ${ }^{4}$ de cada estudo, destacando seu objetivo ou questão de pesquisa, o modo como a questão foi respondida, o contexto e o processo metodológico utilizado, as bases teóricas e principalmente alguns resultados obtidos acerca dos saberes/conhecimentos do PEM. Para isso, utilizamos como corpus de análise/interpretação os fichamentos produzidos pelo projeto do qual este estudo faz parte. Cabe, entretanto, esclarecer que esses fichamentos, tendo em vista nosso objetivo, foram, na maioria dos casos, complementados com informações obtidas por nós a partir de consulta aos trabalhos completos.

As 13 teses que tratam e investigam os saberes e conhecimentos profissionais foram subdivididas em três grupos temáticos, conforme Quadro 02.

Quadro 02: Teses sobre formação continuada que investigam os saberes e conhecimentos profissionais do PEM e seus subfocos temáticos e contextos

\begin{tabular}{|c|c|c|c|}
\hline $\begin{array}{c}\text { Temáticas } \\
\text { do saber } \\
\text { docente }\end{array}$ & Autor da Tese & Subfoco temático & Contexto de FC \\
\hline \multirow{4}{*}{ 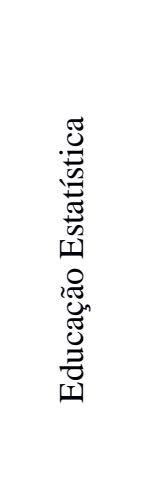 } & Lopes (2003) & \multirow{3}{*}{$\begin{array}{l}\text { Noções de Estatística } \\
\text { e Probabilidade }\end{array}$} & Grupo colaborativo de Educação Infantil na escola \\
\hline & Oliveira (2003) & & $\begin{array}{l}\text { Parceria entre pesquisador e duas professoras do } 2^{\circ} \\
\text { e } 4^{\circ} \text { anos do EF. }\end{array}$ \\
\hline & $\begin{array}{l}\text { Coelho, MVMP } \\
(2010)\end{array}$ & & $\begin{array}{l}\text { Grupo colaborativo fronteiriço entre Universidade- } \\
\text { Escola com professores dos anos finais do EF }\end{array}$ \\
\hline & Novaes (2011) & $\begin{array}{l}\text { Ensino-aprendizagem } \\
\text { de Estatística no EF2 }\end{array}$ & $\begin{array}{l}\text { Grupo de estudo acadêmico de professores dos } \\
\text { anos finais do EF. }\end{array}$ \\
\hline
\end{tabular}

\footnotetext{
${ }^{4}$ Esta síntese não é um resumo. Trata-se de uma elaboração dos autores deste artigo a partir da análise e da interpretação de cada trabalho, destacando os aspectos que interessam ao processo de metassíntese.
} 
DOI: http://dx.doi.org/10.20396/zet.v25i1.8647773

\begin{tabular}{|c|c|c|c|}
\hline & Lemos (2011) & $\begin{array}{l}\text { Compreensão } \\
\text { didático-pedagógica } \\
\text { sobre as Medidas de } \\
\text { Tendência Central }\end{array}$ & Formação continuada em escola dos anos iniciais. \\
\hline \multirow{5}{*}{ 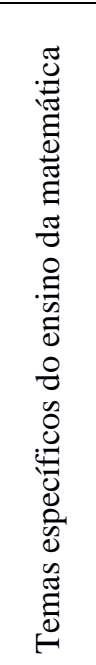 } & Rossini (2006) & Conceito de função & $\begin{array}{l}\text { Curso Extensão PUCSP em contexto } \\
\text { cooperativo/colaborativo. }\end{array}$ \\
\hline & Zulatto (2007) & $\begin{array}{l}\text { Geometria em um } \\
\text { ambiente virtual }\end{array}$ & Formação continuada em ambiente virtual. \\
\hline & Teixeira (2012) & $\begin{array}{l}\text { Contagem } \\
\text { (combinatória) }\end{array}$ & \multirow{2}{*}{$\begin{array}{l}\text { Grupo colaborativo acadêmico vinculado ao } \\
\text { OBEDUC/CAPES, envolvendo pesquisadores e } 23 \\
\text { professores, em subgrupos temáticos }\end{array}$} \\
\hline & Corbo (2012) & $\begin{array}{l}\text { Números } \\
\text { Irracionais }\end{array}$ & \\
\hline & Merlini (2012) & $\begin{array}{l}\text { Campo Conceitual } \\
\text { Multiplicativo }\end{array}$ & $\begin{array}{l}\text { Grupo Colaborativo acadêmico formado entre } \\
\text { a pesquisadora, a orientadora e quatro } \\
\text { professoras do EF }\end{array}$ \\
\hline \multirow{3}{*}{ 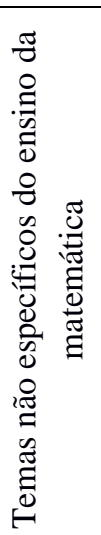 } & Jiménez (2002) & $\begin{array}{l}\text { Ressignificação de } \\
\text { saberes da docência } \\
\text { em matemática }\end{array}$ & $\begin{array}{l}\text { Grupo colaborativo fronteiriço entre Universidade- } \\
\text { Escola }\end{array}$ \\
\hline & Silva (2009) & $\begin{array}{l}\text { Aprendizagens sobre } \\
\text { matemática nas séries } \\
\text { iniciais }\end{array}$ & $\begin{array}{l}\text { Formação continuada em contexto de grupo de } \\
\text { estudos }\end{array}$ \\
\hline & Azevedo (2012) & $\begin{array}{l}\text { Conhecimentos } \\
\text { matemáticos e } \\
\text { metodológicos }\end{array}$ & $\begin{array}{l}\text { Grupo colaborativo fronteiriço entre Universidade- } \\
\text { Escola com professores da Educação Infantil }\end{array}$ \\
\hline
\end{tabular}

Fonte: os autores deste artigo

No primeiro grupo relacionamos cinco trabalhos que têm como foco comum os saberes/conhecimentos docentes relacionados ao campo da Educação Estatística, com ênfase em noções de estatística e probabilidade. Eles foram desenvolvidos em contextos de formação continuada, constituídos por grupos de estudo, envolvendo parceria ou colaboração entre pesquisador(es) e professores.

O estudo de Lopes (2003), por exemplo, buscou compreender o processo de aprendizagem docente em uma prática colaborativa com as professoras da Educação Infantil de uma escola que pouco sabiam sobre esse conhecimento e a possibilidade de explorá-lo nesse nível educativo. Apoiada em aportes teóricos do campo educacional geral (Zeichner, Schön, Hargreaves, Day), da Educação Matemática (D’Ambrosio, Serrazina, Ponte, Llinares...) e da Educação Estatística (Batanero, Gal, Azcárate...), foram desenvolvidos, com as professoras, estudos e experiências de sala de aula e, posteriormente, cada professora escreveu narrativas sobre sua experiência, as quais foram objeto de análise e reflexão 
colaborativa do grupo. Seguindo uma tendência dos estudos dessa natureza, a pesquisadora, para avaliar o desenvolvimento profissional das professoras com destaque para a aprendizagem de conhecimentos profissionais, escreveu narrativas de formação de cada professora. Nesse processo, percebeu que as professoras não desenvolveram apenas um saber-fazer, mas também "promoveram o aprofundamento do conhecimento matemático, estatístico e didático" (Lopes, p. 240), diferenciando o pensamento determinístico do aleatório ou provável.

Oliveira (2003), ao pretender identificar os saberes docentes mobilizados por professoras dos anos iniciais de escolarização em relação a noções de probabilidade, estabeleceu uma parceria com duas professoras, uma do $2^{\circ}$ ano e outra do $3^{\circ}$ ano do EF. Essa parceria consistiu na realização de encontros para desenvolver estudos e planejamentos de tarefas e de aulas, na elaboração de narrativas sobre suas histórias profissionais, na avaliação de suas participações no trabalho de campo, e na intervenção curricular com a presença do pesquisador em suas classes. Embora tenha utilizado "en passant", na revisão bibliográfica e na análise, autores que discutem o conhecimento específico do professor que ensina Estatística (sobretudo o conhecimento de aleatoriedade e de probabilidade), com destaque para Azcárate e Cardeñoso, prevaleceu, tanto em sua revisão bibliográfica quanto em suas análises e produção de resultados e conclusões, os saberes gerais da docência, tendo por base Tardif, Fiorentini e Barth. As professoras parceiras, entretanto, destacaram a importância da parceria, sobretudo a possibilidade de aprendizagem de noções de estatística e de probabilidade e de como explorá-las em suas aulas.

Coelho (2010), por outro lado, constituiu um grupo colaborativo com professoras de escola pública interessadas em estudar, discutir e experienciar a prática de ensinar e aprender Estatística na escola. Tendo como aporte teórico Cochran-Smith e Lytle, formou, com essas professoras, uma comunidade investigativa com o objetivo de planejar e desenvolver experiências próprias relativas ao uso de estatística em suas classes, incluindo um processo de investigação e escrita de reflexões e análises narrativas em relação a essas experiências, mediado pela colaboração do grupo. Interessada em compreender esse movimento do grupo em mobilizar práticas de ensinar e aprender Estatística na escola e em sistematizar os saberes profissionais dos professores neste contexto, interpretou, apoiada em Bahktin e CochranSmith e Lytle, que as professoras passaram a desenvolver, graças à colaboração do grupo, uma prática pedagógica "sensível às histórias, culturas e comunidades locais, relacionando com projetos de outros agentes educacionais e grupos de professores" (p. 69). Além disso, percebeu que

quando as professoras do grupo passaram a adotar, em relação ao conhecimento, uma postura investigativa que envolvia questionamento, seus alunos passaram também a fazer mais perguntas e a estabelecer, por meio da estatística, mais relações entre os fatos discutidos em sala de aula e suas práticas cotidianas. (p.173)

O trabalho de Novaes (2011), por sua vez, buscou analisar as concepções didáticas e conceituais de Estatística, com destaque para o conceito de variabilidade, mobilizadas por dois professores que participaram de um projeto com um grupo acadêmico de formação Zetetiké, Campinas, SP, v.25, n1, jan./abr.2017, p.164-185 
continuada de professores dos anos finais do EF, desenvolvido ao longo de três anos na PUCSP, que tiveram oportunidade de preparar sequências didáticas e aplicá-las em sala de aula. Para isso, tomou como suporte teórico-metodológico a didática francesa (Teoria das Concepções, de Ballacheff e Gaudin, e a Teoria dos Campos Conceituas, de Vergnaud), complementando, com menor ênfase, para o caso dos conhecimentos específicos sobre ensino de estatística e probabilidade (Batanero, Gal e Franklin) ou dos conhecimentos profissionais sobre ensino (Shulman). Além de ter identificado "16 concepções didáticas e estatísticas que funcionam inter-relacionadas", destacou a resistência dos professores em romper com o pensamento determinista no tratamento de dados - fato conseguido, neste estudo, graças ao tempo prolongado (três anos) de formação continuada e a oportunidade de os professores não apenas aplicarem as sequências didáticas em sala de aula, mas, principalmente, analisarem, discutirem e problematizarem suas práticas letivas.

Lemos (2011) teve como foco de estudo a compreensão e o desenvolvimento didático-pedagógico do conteúdo de professores que atuam nos anos iniciais do EF sobre "as Medidas de Tendência Central, a partir da investigação de seu desenvolvimento profissional numa formação continuada" (p. 27). Participaram do processo seis professoras dos anos iniciais, tendo desenvolvido um trabalho de campo em cinco etapas: 1) aplicação de uma sequência de ensino em um curso de Estatística, organizado em cinco encontros; 2) elaboração de uma tarefa; 3) análise da tarefa elaborada; 4) aplicação da tarefa em sala de aula, e 5) realização do processo de análise e discussão da aplicação da tarefa em sala de aula e sobre todo o processo de intervenção vivenciado. Os dados provenientes das interações com as professoras no momento do desenvolvimento e da análise de tarefas relacionadas à Estatística foram analisados com base em Cobo e Batanero, Godino, Strauss e Bichler, entre outros. Os resultados destacaram a apropriação dos conceitos de média, moda e mediana e de suas propriedades, não apenas no momento da elaboração das tarefas, mas, principalmente, durante a análise e a discussão da aplicação da tarefa em aula. Um indício, por exemplo, de desenvolvimento da produção de significados para a média, foi percebido quando as professoras, ao longo da intervenção, passaram a considerar também o valor (ou a frequência) zero no cálculo da média.

Fazendo uma síntese integrativa dos trabalhos desse primeiro grupo, podemos destacar que os conhecimentos conceituais e didático-pedagógicos de estatística e probabilidade foram trazidos pelos formadores-pesquisadores a partir de uma literatura acadêmica especializada (Batanero, Gal, Azcárate...), principalmente nos estudos de Lopes (2003), Novaes (2011) e Lemos (2011). Os dois últimos citam Shulman para fazer referência a esses tipos de conhecimentos, entretanto, para contemplar a especialidade do conhecimento estatístico e probabilístico, mas buscam complementação nos estudos de Batanero, Azcárate, entre outros. Novaes (2011), além deles, buscou apoio teórico em Vergnaud e na Didática Francesa (Ballacheff e Gaudin) para analisar as concepções didáticas e estatísticas. Por outro lado, Oliveira (2003) e Coelho (2010), por priorizarem mais a prática pedagógica em estatística e probabilidade, preferiram utilizar autores que abordam questões e conceitos 
(saberes) mais gerais e relativos ao trabalho docente, como é o caso de Tardif, Barth, Cochran-Smith e Lytle, entre outros.

Cabe destacar, por outro lado, que a aprendizagem de conhecimentos específicos sobre ensino de estatística e probabilidade por parte dos professores envolvidos em um processo de formação continuada foi concretizada não apenas porque estudaram/discutiram conceitualmente esses conhecimentos, mas, principalmente, porque puderam situá-los e analisá-los no contexto de suas práticas de sala de aula. Essa prática de desenvolvimento profissional parece ter feito diferença na qualidade da aprendizagem desses conhecimentos, embora esse processo exija tempo prolongado e contínuo, permeado pela análise e pela problematização das práticas de ensinar e aprender. Isso parece ter ocorrido em todos os estudos analisados, sendo, porém, mais evidente nos estudos de Lopes (2003) e Novaes (2011), pois estes pesquisadores destacaram a percepção da ruptura do pensamento determinista, característica muito presente entre professores de matemática que ensinam estatística. Outro aspecto interessante a destacar é que essa aprendizagem docente, em termos de mudança de concepção, em um contexto de formação em serviço, permeada pela experimentação e pela análise de práticas de sala de aula, reverberou em sua prática profissional no sentido de que o professor passou a promover, nas escolas, uma educação matemática e estatística mais crítica.

O segundo grupo de pesquisas reúne cinco teses que têm como foco temático comum de estudo os conhecimentos docentes relativos ao ensino de temas específicos de matemática: função (Rossini, 2006); geometria (Zulatto, 2007); combinatória (Teixeira, 2012); números irracionais (Corbo, 2012); e campo conceitual mutiplicativo (Merlini, 2012).

Rossini (2006), ao tentar responder "como os professores (re)constroem seus saberes docentes sobre o conceito de função?” (p.23) - tomou como apoio teórico uma combinação entre os conhecimentos profissionais com base em Shulman e a Teoria Antropológica do Didático, de Chevallard. Para Chevallard (citado por Rossini, 2006, p. 326), o saber docente refere-se ao saber relativo a uma organização matemática, cujos ingredientes são: tarefa, técnica, tecnologia da técnica e teoria. Nesse estudo, o conhecimento do conteúdo e o conhecimento pedagógico do conteúdo sobre funções, conforme Shulman, foram tratados, com base em Chevallard, "em termos de organização matemática e organização didática" (p. 325). Rossini (2006), assim, concebeu o conhecimento pedagógico do conteúdo como a "maneira que cada professor possui para transformar conteúdo científico da matemática em conteúdo escolar, a ser ensinado ao aluno" (p. 23). O trabalho de campo foi realizado com um grupo de professores da rede pública estadual, em um ambiente de colaboração entre a pesquisadora e os professores, quando eles puderam elaborar e aplicar conjuntamente sequências didáticas, experienciando diversos papéis; "construtor e analista da sequência de ensino"; "observador e analista crítico do que foi observado em sua própria prática docente"; "socializador de suas reflexões individuais sobre a observação" (p.336). Ao aproximar-se de uma prática formativa colaborativa, colocando em questão tanto o conhecimento prévio trazido pelos professores como o conhecimento acadêmico, rompeu com alguns pressupostos 
da transposição didática, pois abriu oportunidade para que os professores pudessem construir sequências didáticas em situação de diálogo entre suas crenças e experiências acumuladas e os conhecimentos acadêmicos. Nesse processo, concluiu que os professores: "(re)construíram seus saberes sobre função" (p. 329); "ampliaram seus conhecimentos sobre as dificuldades dos alunos, bem como sobre suas potencialidades (p. 330); descontruíram a crença de que "os alunos assimilavam a linguagem algébrica, tomando contato com textos de linguagem algébrica, seguida por um exercício resolvido" (p. 333), e passaram a valorizar situaçõesproblema que exploram o conceito de função e a construção da linguagem algébrica.

O estudo de Zulatto (2007), por sua vez, objetivou analisar, de um lado, como acontece a aprendizagem matemática dos professores que participam de um projeto de extensão online de formação continuada em Geometria (mediado pelo software Geometricks) e, de outro, como eles desenvolvem, nesse contexto, as discussões de cunho matemático, a comunicação das ideias, de que maneira eles expressam seu raciocínio e interagem ente si e as tecnologias. O projeto de extensão envolveu a participação online de professores de uma rede de escolas de diferentes partes do Brasil, com interações, em tempo real, por chat ou videoconferência. Em síntese, os resultados apontaram que, nesse contexto, a aprendizagem matemática (geometria) foi colaborativa, e "argumentativa, uma vez que conjecturas e justificativas matemáticas se desenvolveram intensamente do decorrer do processo, contando, para isso, com as tecnologias presentes na interação ocorrida de forma constante e colaborativa" (p.132).

Duas teses desse subgrupo tiveram como foco de estudo o conhecimento conceitual específico e pedagógico de número irracional (Corbo, 2012) e de combinatória (Teixeira, 2012) do PEM em um mesmo contexto de formação continuada, constituído por um grupo colaborativo de formação e pesquisa, envolvendo pesquisadores, professores da rede pública de ensino e pós-graduandos vinculados a um subprojeto ODEBUC/CAPES.

Dentre as perguntas investigativas de Teixeira (2012), interessa-nos a seguinte: "Quais são os conhecimentos de um grupo de professores a respeito da resolução de Problemas de Contagem e suas concepções sobre o desenvolvimento desse tema no Ensino Fundamental?" (p. 33). Uma das fases de coleta de dados desta pesquisa consistiu em uma intervenção realizada segundo princípios da metodologia Design Experiments de Cobb e colaboradores, para verificar "se uma sequência de atividades que explore a resolução de Problemas de Contagem, sem uso de fórmulas, pode favorecer a ressignificação dos conhecimentos"(p. 42) matemático, didático e curricular dos professores sobre ensino de combinatória. Apoiado teoricamente, de um lado, em Tall e Vinner, em relação à "imagem conceitual" e, em Fischbein, sobre os "componentes formais, intuitivos e algorítmicos" da atividade matemática e, de outro, em Shulman, acerca dos conhecimentos do professor e Zeichner, sobre professor reflexivo, verificou que os professores ampliaram os conhecimentos matemáticos e pedagógicos sobre combinatória, ao longo do processo, permanecendo, entretanto, uma forte tensão entre aqueles que defendiam a necessidade do uso de fórmulas para validar as respostas encontradas e aqueles que as descartavam. 
A tese de Corbo (2012), por sua vez, teve por objetivo "investigar os conhecimentos necessários ao professor, sob os pontos de vista do conteúdo, didático e curricular, para ensinar o conceito de número irracional na Educação Básica” (p. 17). Além de uma fase diagnóstica inicial, a partir de questionários, a $2^{\mathrm{a}}$ fase contou com o desenvolvimento de um Design Experiments ( $D E)$, conforme Cobb e colaboradores, visando verificar se "uma sequência de atividades que explore a percepção de que os pontos de coordenadas racionais não esgotam toda a reta numérica poderia favorecer a ampliação e/ou reconstrução do conhecimento dos professores, relativo aos números irracionais" (p. 199). Além de se apoiar teoricamente nos mesmos autores de Teixeira (2012), utilizou também Ball et al. (2008), acerca das categorias do conhecimento profissional do PEM, notadamente o "conhecimento do conteúdo comum/especializado, conhecimento do conteúdo e do estudante, conhecimento do conteúdo e do ensino e conhecimento curricular" (p. 20). A partir do diagnóstico inicial no qual os professores revelavam concepções inconsistentes sobre os números racionais e irracionais, a fase de intervenção relativa ao $D E$ ocorreu ao longo de seis encontros e evidenciou que os professores ampliaram a imagem conceitual desses números e mobilizaram conhecimentos do "conteúdo especializado, envolvendo um tipo de conhecimento e raciocínio matemático que vai além daquele exigido, por exemplo, para a execução de tarefas do cotidiano" (p. 211), para a resolução de exercícios e problemas tradicionais da matemática escolar, ou para o reconhecimento não apenas dos erros dos alunos, mas principalmente da "fonte desses erros" (p. 214). Outros exemplos de conhecimento especializado foram apresentados e discutidos com os professores como, por exemplo, justificar/provar (algebricamente e geometricamente) que "raiz quadrada de 5" é um número irracional (p. 223). Os professores investigados passaram a perceber também a importância do componente formal, no corpo de conhecimentos necessários ao professor, sobre números irracionais, como evidencia o depoimento de um professor: "o prof. precisa ter um domínio e aprofundamento sobre os $\mathrm{n}^{\text {os }}$ irracionais que ultrapassem o conteúdo que ele pretende transmitir ao aluno, pois o conj. dos $n^{o s}$ irracionais é complexo e de difícil assimilação" (p. 234).

Merlini (2012), em seu objetivo investigativo, não fez referência direta aos saberes ou conhecimentos docentes que resultaram de um processo colaborativo de formação continuada, envolvendo uma ação teórica (de estudo e planejamento de atividades relativas ao Campo Conceitual Multiplicativo (CCM) com base em Vergnaud), uma ação prática (de pré-análise e intervenção em sala de aula, com escrita de relatório) e uma ação reflexiva (de reflexão sobre os resultados da intervenção e escrita de relatório). Entretanto, sua análise e os resultados relativos ao caso de uma professora do $3^{\circ}$ ano participante do grupo tiveram como foco analítico os "conhecimentos teóricos e práticos de uma professora em relação ao CCM, evidenciados por meio da vivência e da reflexão", trazendo outras contribuições sobre o processo de produção e ressignificação dos conhecimentos profissionais do PEM. Embora fizesse referência a Shulman quanto aos conhecimentos do conteúdo e didático do conteúdo, foi em Vergnaud que encontrou suportes conceituais específicas ao CCM para analisar a aprendizagem de conhecimentos da professora, tendo verificado, por exemplo, que, durante o 
processo formativo, ela percebeu que houve, de um lado, "expansão dos conhecimentos do CCM" e, de outro, algumas dificuldades de natureza conceitual como, por exemplo, confundir "uma situação de divisão partitiva com uma situação de divisão quotitiva", tendo inclusive, não explorado em sala de aula situações de divisão quotitiva (p. 166). A pesquisadora acredita que essa dificuldade tenha sido decorrente do tempo restrito de formação continuada da professora, o qual levou aproximadamente um semestre. Do ponto de vista dos conhecimentos didáticos, a professora aprendeu a valorizar a aprendizagem compartilhada e, mediante interação, permitiu que estudantes expressassem seus raciocínios.

Fazendo uma pequena síntese integrativa dos trabalhos deste segundo grupo, podemos destacar que os conhecimentos conceituais e didático-pedagógicos relativos a temas específicos da matemática foram bastante restritos em comparação com os do grupo de estatística e probabilidade. Quatro dos cinco trabalhos fazem referência a Shulman para falar dos conhecimentos profissionais do professor, e todos eles buscam complementação em outros aportes do campo da educação matemática para tentar dar conta da especificidade desses conhecimentos. Por exemplo, Rossini (2006) e Merlini (2012) buscam, respectivamente, aportes complementares em Chevallard (para o caso do ensino de funções) e em Vergnaud (para o caso do CCM). Corbo (2012) e (Teixeira (2012) buscam aportes complementares em Fischbein e em Tall e Vinner sobre imagem conceitual de professores e a importância de integrar na atividade matemática os componentes formais, intuitivos e algorítmicos. Além disso, Corbo (2012) buscou aportes em Ball e colaboradores, para tratar do conhecimento especializado do professor sobre números irracionais. Zulatto (2007) foi a única que não utilizou aportes sobre conhecimentos profissionais para discutir a formação continuada de professores de Matemática sobre ensino de Geometria em ambiente virtual, tendo priorizado, em suas análises, os aspectos relacionados ao uso de tecnologia no ensino e na formação docente.

Outro aspecto a destacar é que todos estes trabalhos também utilizaram aportes oriundos do campo geral da educação, tais como Zeichner, Mizukami, Nóvoa, Tardif, Gauthier (para tratar da formação de professores reflexivos e/ou investigativos) ou do campo da educação matemática, em relação à possibilidade de o professor investigar sua prática em ambiente de colaboração com formadores da universidade (Ponte, Fiorentini, Ferreira, Nacarato...). Aliás, a formação em serviço de professores que ensinam matemática em grupos colaborativos - e seu impacto na aprendizagem de conhecimentos e no desenvolvimento profissional - foi um contexto comum a todos os cinco trabalhos deste grupo.

As outras três teses foram alocadas em um terceiro grupo, por não focarem um conteúdo específico da matemática para investigar os saberes docentes. O mais antigo é o de Jiménez (2002) que investigou "o processo de mobilização e ressignificação de saberes em um ambiente de trabalho colaborativo" (p. 67), tendo acompanhado o processo de formação continuada de um grupo colaborativo fronteiriço (Grupo de Sábado), entre escola e universidade. $\mathrm{O}$ foco principal de estudo do grupo foram os problemas e práticas de ensino e aprendizagem de matemática nas escolas, mediado por leituras e problematizações da prática 
docente dos professores participantes. Tendo como aportes teóricos Tardif, Barth, CochranSmith e Lytle e Fiorentini (em relação aos saberes e conhecimentos do professor) e Bakhtin (em relação à análise de discurso numa perspectiva dialógica), analisou episódios de reflexão e análise dos professores sobre práticas e saberes relativos ao ensino e à aprendizagem da matemática, com a colaboração de acadêmicos da universidade. Os resultados do estudo mostram que a "re-significação de saberes e práticas pôde ser observada como um processo permanente de tensão", envolvendo, de um lado, "aspectos, particularidades e saberes experienciais de sala de aula levados pelos professores escolares, e de outro, as problematizações feitas pelos acadêmicos", com base em pesquisas. O estudo constatou que, quando o objeto da reflexão é "a prática discursiva que acontece em sala de aula, as discussões tornam-se mais ricas e contributivas para os processos de ressignificação de saberes da ação pedagógica em Matemática" (p. VIII). Evidenciou, entretanto, uma diferença no modo de atuação e de produção de saberes profissionais entre os professores e os acadêmicos. Enquanto os professores escolares se destacavam em produzir reflexões e ressignificações (isto é, conhecimentos) sobre o que sabem e fazem na prática cotidiana, os acadêmicos tentam fazer problematizações, sínteses e sistematizações sobre os conhecimentos que os professores aprendem no grupo.

O segundo trabalho do subgrupo que não focou um conteúdo específico da matemática é o de Silva (2009), que analisou aprendizagens de professoras dos anos iniciais participantes de uma formação continuada ocorrida num grupo de estudos sobre matemática. A aprendizagem incidiu sobre aspectos didático-pedagógicos e sobre conhecimentos dos conteúdos matemáticos, principalmente geometria e resolução de problemas envolvendo as quatro operações. Ao longo da tese, diversas interações com as participantes foram descritas. A pesquisadora concluiu que, ao longo do processo, foi possível notar nas professoras participantes dessa pesquisa, que "elas tiveram algumas 'novas' formas de ver, conceber, pensar e fazer a matemática, seu ensino, aprendizagem e avaliação, em suas salas de aula" [ênfase no original] (p. 276). A autora apoiou sua análise sobre aprendizagem nos estudos de Santos, Chapman, Mizukami, entre outros. Como seu foco eram as aprendizagens, os conhecimentos específicos não foram tratados conceitualmente, entretanto, concluiu que "algumas aprendizagens de conteúdos matemáticos que ficaram mais evidentes e significativas foram aquelas relacionadas à resolução de problemas, envolvendo as quatro operações e a geometria" (p. 300).

Azevedo (2012), para responder sua questão investigativa - "Quais conhecimentos matemáticos e metodológicos são produzidos, reconhecidos e ressignificados por professoras da Educação Infantil?" em um contexto colaborativo entre pesquisadora e professoras - criou o "Grupo de Estudos Outros Olhares para a Matemática" (GEOOM) que funcionou, ao longo de três anos, em um Centro Municipal de Educação Infantil e "tornou-se um espaço de compartilhamento de experiências e reflexões das professoras da Educação Infantil sobre o desafio de trabalhar o conhecimento matemático com as crianças" (p. 198). Tomando a prática das professoras participantes como ponto de partida, foram desenvolvidas atividades formativas envolvendo leitura e discussão de textos e principalmente experiências com jogos Zetetiké, Campinas, SP, v.25, n1, jan./abr.2017, p.164-185

ISSN 2176-1744 
como boliche, tiro ao alvo, amarelinha, dominó... em que as professoras não apenas discutiam e experienciavam esses jogos, mas também compartilhavam experiências de implementação na escola. Ou seja, foi um processo rico de formação continuada com atividades potenciais de exploração de noções matemática, como mostram as narrativas produzidas pelas professoras, envolvendo contagem e registros de modo informal, simbólico ou gráfico das pontuações. Concluiu, ancorada em Shulman e Mizukami e em outros mais específicos da educação matemática infantil (Lorenzato, Passos, Nacarato), que

a produção, o reconhecimento e a ressignificação dos conhecimentos matemáticos aconteceram a partir dos aspectos conceituais desencadeados pela aprendizagem colaborativa e relacionados aos conhecimentos matemáticos e aos conhecimentos metodológicos que, redimensionados pelas professoras, se revelaram nas narrativas orais e escritas(p. 197).

O trabalho traz situações formativas e de aprendizagem docente que poderiam, mediante análise meticulosa, contribuir para explicitar e compreender o conhecimento especializado de matemática que as professoras da Educação Infantil mobilizam e projetam como possível de ser trabalhado no contexto da Educação Infantil e que se diferencia, em natureza, do conhecimento especializado de matemática normalmente trabalhado no EF.

Fazendo uma síntese integrativa dos três últimos trabalhos, destacamos, primeiramente, a diferença de concepção e a busca de aportes teóricos e do modo de investigar os saberes e conhecimentos profissionais em um contexto de formação em serviço também marcado pela colaboração, contrastando, assim, com os dois grupos anteriores,

De fato, acreditamos que o fato de esses trabalhos terem priorizado, como ponto de partida da formação continuada, as práticas profissionais dos professores e suas necessidades, não havendo a priori a delimitação de um campo conceitual específico da matemática, tenha contribuído para que os objetos de estudo desses trabalhos tenham sido as práticas letivas dos professores participantes e os saberes docentes aí mobilizados e problematizados. Isso parece mais evidente no caso do estudo de Jiménez (2002), que investigou o Grupo de Sábado, o qual tem sido considerado por Fiorentini e Carvalho (2015) como uma comunidade fronteiriça entre a escola e a universidade por possuírem uma agenda própria de trabalho e estudo, sem serem monitoradas institucionalmente por estas instituições. Entretanto o que se aprende nesta comunidade tem forte impacto na vida pessoal e profissional de seus participantes. Ou seja, neste contexto de formação continuada, não faz sentido a transposição didática dos conhecimentos considerados pelos acadêmicos como fundamentais para o ensino da matemática. Isso não significa que a comunidade local de professores negue esses conhecimentos. O que muda é o papel que esses conhecimentos, oriundos das pesquisas acadêmicas, passam a ter no texto da prática escolar. Estes conhecimentos continuam a ser referência importante no contexto da formação docente e, geralmente, são trazidos e mobilizados pelos formadores do grupo para problematizar, ressignificar e transformar as práticas de ensinar matemática nas escolas. Nesse contexto, como bem discutem Moreira e David (2005), a Matemática escolar e a Matemática acadêmica são de naturezas diferentes, e a primeira não deve ser a imagem e semelhança da segunda. Mas também não pode ignorá-la. 
O problema metodológico e epistemológico da pesquisa de casos como os que compõem este grupo é que não temos ainda um referencial teórico e metodológico que possa ajudar os pesquisadores a analisar como os conhecimentos e os saberes profissionais dos professores são problematizados, tecidos na prática escolar, sobretudo em contextos de grupos colaborativos entre universidade e escola. Um indício disso é o fato de os pesquisadores desses três trabalhos terem buscado aportes em autores que procuram uma maior aproximação com o trabalho docente, efetivamente desenvolvido nas escolas, como é o caso de Tadif, Gauthier, Day e Cochran-Smith, Mizukami entre outros. Mas há também referências aos trabalhos de Shulman (Azevedo, 2012) e de autores da área de Educação Matemática, voltados ao estudo da formação de professores vinculados às práticas profissionais, como é o caso de Ponte, Jaworski, Llinares, Fiorentini, Nacarato e Passos.

\section{Balanço síntese e considerações finais}

Fazendo um pequeno balanço das teses de doutorado relativas à aprendizagem ou à mobilização de saberes e conhecimentos profissionais do PEM, em um contexto de formação continuada, é possível perceber três tendências.

A primeira tendência vem do campo da educação em geral, tendo por base geralmente Tardif et al. (1991), Gauthier e Tardif (1997), Shulman (1986 e 1987), Day, Zeichner, Schön, Barth, Mizukami, entre outros. Os estudos dessa tendência, como foi evidenciado em alguns poucos trabalhos desta metassíntese, tentam investigar os saberes e conhecimentos mobilizados e produzidos pelos professores no contexto da formação em serviço de professores, mas não estabelecem diálogo mais profundo com a especificidade do campo da educação matemática

Uma segunda tendência tenta estabelecer aproximação à especificidade do campo da educação matemática ou da educação estatística. Embora utilizem referenciais gerais com base em Tardif et al. (1991), Shulman (1986, 1987), Zeichner, Day, Cochran-Smith e Lytle (1999), Leontiev, entre outros, utilizam também referenciais construídos por autores do campo da educação matemática ou da educação estatística que tentaram adaptar esses referenciais para o campo da educação matemática, tais como os trabalhos mais recentes de Ponte, Serrazina, Llinares, Azcárate, Fiorentini, Nacarato, Lopes e Passos etc. Esses trabalhos avançam em relação aos da primeira tendência no sentido de tentar estabelecer uma maior aproximação e compreensão da complexidade das práticas de ensinar e aprender estatística e/ou matemática e tentam investigar os conhecimentos e saberes mobilizados e produzidos pelos professores no contexto da formação em serviço de professores que atuam na Educação Infantil (como é caso de Azevedo, 2012), ou participam de grupos colaborativos que ficam na fronteira entre a universidade e a escola (como é o caso de Jiménez, 2002) e que priorizam a prática docente nas escolas como ponto de partida e de chegada da formação continuada.

Se, de um lado, os estudos dessas duas tendências, devido à falta de um referencial mais apropriado a esse campo de estudo, parecem subestimar ou omitir análises e compreensões mais profundas, detalhadas e circunstanciadas da atividade matemática (e do 
tipo de conhecimento profissional mobilizado e requerido do professor) em interação nas práticas de ensinar e aprender dos professores, de outro, esses estudos podem trazer contribuições e compreensões importantes acerca do trabalho e de natureza do conhecimento matemático e didático-pedagógico possível e pertinente neste contexto. Uma metassíntese desses trabalhos poderia ajudar a sistematizar esses conhecimentos e contribuir para a construção de um modelo de conhecimento profissional que se situa na interface entre os resultados das pesquisas acadêmicas e as evidências das práticas profissionais investigadas e sistematizadas pelos professores em grupos colaborativos.

A terceira tendência busca aportes mais específicos aos campos de conhecimento do ensino e aprendizagem da matemática ou da estatística, apoiando-se em autores tais como: Vergnaud (para os Campos Conceituais Aditivos e Multiplicativos); Moreira (Números Reais); Brousseau, Chevallard, Ballacheff entre outros (relacionados à didática matemática francesa), Batanero, Gal, Azcárate, Lopes e Coutinho (para o ensino de estatística e probabilidade ou letramento estatístico); Ball et al.(2008) acerca dos "domínios de conhecimento matemático do professor para o ensino", estando presente apenas no trabalho de Corbo (2012). Tem surgido, mais recentemente, outros referenciais no âmbito desta tendência - como é o caso de Carrillo et al. (2013) e seus colaboradores - que surgiram após fecharmos o corpus de metassíntese desse estudo.

Embora essa perspectiva, menos frequente, ainda necessite de refinamento e adequação ao contexto da formação continuada, certamente pode trazer contribuições específicas importantes à aprendizagem docente, sobretudo em termos dos conhecimentos profissionais especializados em matemática escolar e que, certamente podem ajudar a repensar a formação matemática e didático-pedagógica da matemática nos cursos de licenciatura em matemática e pedagogia.

Há muito ainda a se conhecer quanto à natureza e a especificidade dos saberes e conhecimentos profissionais mobilizados e investigados pelas teses de doutorado, no contexto da formação continuada do PEM, sobretudo em contextos de prática escolar, seja inovadora ou vigente nas escolas. Entendemos que a especificidade, priorizada pela última tendência, pode ficar fragilizada se limitar a uma perspectiva estritamente disciplinar ou acadêmica e não situar essa especificidade em um contexto mais amplo - não disciplinar ou interdisciplinar - das práticas pedagógicas, como evidenciamos em alguns estudos. Ou seja, um dos desafios dos estudos sobre a aprendizagem de conhecimentos profissionais é não deixar de situar ou contemplar, em suas análises, também as dimensões culturais e políticas que afetam o fazer docente do PEM, tanto em situações de inovação pedagógica - como foi a tônica dos estudos aqui analisados - como também em contextos vigentes da prática de ensinar e aprender matemática nas escolas e no contexto das políticas públicas.

Além disso, o mapeamento inicial dos principais focos temáticos investigados pelas 46 pesquisas de doutorado sobre formação continuada do PEM parece consolidar uma tendência considerada pelo estudo anterior (Fiorentini et al., 2002) apenas emergente. De fato, aquele estudo mostrou que, antes do ano 2000, os cursos de treinamento ou reciclagem docente foram 
predominantes nas décadas de 1970 e 1980, bem como os estudos para ou sobre professores que continuaram frequentes durante os anos de 1990. Entretanto, a partir dos anos 2000, aquele estudo apontava o surgimento de estudos com professores, estabelecendo parcerias ou grupos colaborativos de estudo conjunto entre universidade e escola ou entre formadores/pesquisadores e professores escolares. No mapeamento atual, de 2001 a 2012, mais de $80 \%$ das teses de doutorado sobre formação continuada promoveram contextos formativos que compreendiam trabalho conjunto ou colaborativo entre universidade e escola, envolvendo, em muitos casos, os professores em processos de intervenção sem sua própria prática, mediados pela reflexão e pela investigação dessa prática. No que tange às relações entre conhecimentos/saberes profissionais e prática letiva, na perspectiva de Cochran-Smith e Lytle (1999), podemos, em síntese, dizer que os estudos revisados nesta metassíntese mobilizaram, discutiram e problematizaram: os conhecimentos profissionais a partir de estudos acadêmicos, na perspectiva PARA a prática; os saberes da docência produzidos e mobilizados NA e a partir da prática; e os conhecimentos DA prática, à medida que esses conhecimentos e saberes são tomados como objeto de estudo pelos professores.

Em síntese, os resultados deste estudo apontam para a necessidade de uma adequada articulação entre as perspectivas - geral e específica ou acadêmica e escolar - relativas aos conhecimentos que perpassam a prática do PEM. Acreditamos que os projetos de formação continuada do PEM, por exemplo, poderiam envolver, sempre que possível, professores, futuros professores, formadores de professores e pesquisadores acadêmicos, em comunidades de aprendizagem. Nas teses, aqui analisadas, encontramos indícios para afirmar que as práticas formativas não devem se reduzir apenas ao estudo do que acontece em sala de aula, mas incluir, também, aquilo que a antecede, isto é, o planejamento (de aulas, tarefas, situações-problema, sequências didáticas etc), a implementação desse planejamento (registrando/documentando suas ações, interações e produções) e, sobretudo, a reflexão, a análise e a problematização do planejamento e da respectiva prática letiva. Esta perspectiva de formação contínua e de pesquisa é ainda um campo aberto de estudo, sobretudo no contexto brasileiro, e que não pode realizar-se sem a participação dos formadores, pesquisadores e professores da escola básica, em processo de parceria.

\section{Referências}

Ball, D., Thames, M. H., \& Phelps, G. (2008). Content Knowledge for Teaching: What makes it special? Journal of Teacher Education, 59(01), 389-407.

Carr, W., \& Kemmis, S. (1988). Teoria crítica de la enseñanza: la investigación-acción en la formación del profesorado. Barcelona: Ediciones Martinez Roca.

Carrillo, J., Climent, N., Contreras, L. C. \& Muñoz-Catalán, M. C. (2013). Determining Specialized Knowledge for Mathematics Teaching. In B. Ubuz, C. Haser, \& M. A. Mariotti (Eds.), Proceedings VIII Congress of the European Society for Research in 
DOI: http://dx.doi.org/10.20396/zet.v25il.8647773

Mathematics Education (CERME 8) (pp. 2985-2994). Antalya: Middle East Technical University, Ankara.

Cochran-Smith, M., \& Lytle, S. L. (1999). Chapter 8: Relationships of knowledge and practice: Teacher learning in communities. Review of research in education, 24(1), 249305 .

Fiorentini, D. (2000). Pesquisando com professores - reflexões sobre o processo de produção e ressignificação dos saberes da profissão docente. In J. F. Matos, \& E. Fernandes (Eds), Investigação em Educação Matemática - perspectivas e problemas (pp. 187-195). Lisboa: APM, p. 187-195.

Fiorentini, D. (2013). A Investigação em Educação Matemática desde a perspectiva acadêmica e profissional: desafios e possibilidades de aproximação. Cuadernos de Investigación y Formación en Educación Matemática, 1(8), 61-82.

Fiorentini, D., \& Carvalho, D. L. (2015). O GdS como lócus de experiências de formação e aprendizagem docente. In D. Fiorentini, F. L. P. Fernandes, D. L. Carvalho (Orgs.), Narrativas de práticas de aprendizagem docente em matemática (1ed., vol. 1, pp.15-37). São Carlos: Pedro \& João Editores.

Fiorentini, D., \& Coelho, M. A. V. M. (2012). Aprendizagem profissional de professores em comunidades investigativas. Leitura. Teoria \& Prática, 58(30), 1053-1062.

Fiorentini, D., Nacarato, A., \& Pinto, R. A. (1999). Saberes da experiência docente em matemática e educação continuada. Quadrante: Revista Teórica e de Investigação, 8(12), 33-60. Lisboa: APM.

Fiorentini, D., Nacarato, A.M., Ferreira, A. C., Lopes, C. A. E., Freitas, M. T. M., Miskulin, R. G. S. (2002). Formação de professores que ensinam Matemática: um balanço de 25 anos da pesquisa brasileira. Educação em Revista 36, 137-160.

Fiorentini, D., Passos, C. L. B., Lima, R. C. R. (Org.). (2016). Mapeamento da pesquisa acadêmica brasileira sobre o professor que ensina Matemática: Período 2001 a 2012 (1a ed.). Campinas: FE-Unicamp. Retirado em dezembro de 2016, de[ https://www.fe.unicamp.br/biblioteca/e-book- mapeamento-pesquisa- PEM].

Fiorentini, D., Souza Jr, A., \& Melo, G. A. (1998). Saberes docentes: um desafio para acadêmicos e práticos. In C. M. G. Geraldi, D. Fiorentini, \& E. M. Pereira (Orgs), Cartografias do Trabalho Docente: professor(a)-pesquisador(a) (pp.307-335). Campinas: ALB e Mercado de Letras.

Gauthier, C., \& Tardif, M. (1997). Elementos para uma análise crítica dos modos de fundação do pensamento e da prática educativa. Contexto e Educação, 12(48), 17-39. Ijuí: Ed. Unijuí. 
DOI: http://dx.doi.org/10.20396/zet.v25i1.8647773

Godfrey, M., \& Denby, T. (2006). The methodology of systematic reviews: conception of the process. Centre for health and Social Care, Institute of Health Science and Public Research: University of Leeds.

Moreira, P. C., \& David, M. M. M. S. (2006). A formação matemática do professor: licenciatura e prática docente escolar. Belo Horizonte: Autêntica.

Shulman, L. S. (1986). Those who understand: Knowledge growth in teaching. Educational Researcher, 15(2), 4-14.

Shulman, L. S. (1987). Knowledge and teaching: Foundations of the new reform. Harvard Educational Review, 57(1), 1-22.

Tardif, M., Lessard, C., \& Lahaye, L. (1991). Os professores face ao saber - esboço de uma problemática do saber docente. Teoria \& Educação, 01(4), 215-133.

\section{APÊNDICE 1: Relação das teses do corpus de análise deste estudo}

Azevedo, P. D. (2012). O conhecimento matemático na Educação Infantil: o movimento de um grupo de professoras em processo de formação continuada. Tese de Doutorado, São Carlos: Universidade Federal de São Carlos.

Coelho, M. A. V. M. (2010). Os saberes profissionais dos professores: a problematização das práticas pedagógicas em estatística mediadas pelas práticas colaborativas. Tese de Doutorado. Campinas: Universidade Estadual de Campinas.

Corbo, O. (2012). Um estudo sobre os conhecimentos necessários ao professor de Matemática para a exploração de noções concernentes aos números irracionais na Educação Básica. Tese de Doutorado. São Paulo: Universidade Bandeirante.

Jimenez, E. A. (2002). Quando professores de Matemática da escola e da universidade se encontram. Tese de Doutorado. Campinas: Universidade Estadual de Campinas.

Lemos, M. P. F. (2011). O desenvolvimento profissional de professores do $1^{o}$ ao $5^{o}$ ano do Ensino Fundamental em um processo de formação para o ensino e a aprendizagem das medidas de tendência central. Tese de Doutorado. São Paulo: Pontifícia Universidade Católica de São Paulo.

Lopes, C. A. E. (2003). O conhecimento profissional dos professores e suas relações com estatística e probabilidade na Educação Infantil. Tese de Doutorado. Campinas: Universidade Estadual de Campinas.

Merlini, V. L. (2012). As potencialidades de um processo formativo para a reflexão na e sobre a prática de uma professora das séries iniciais: um estudo de caso. Tese de Doutorado. São Paulo: Pontifícia Universidade Católica de São Paulo. 
DOI: http://dx.doi.org/10.20396/zet.v25i1.8647773

Novaes, D. V. (2011). Concepções de professores da educação básica sobre variabilidade estatística. Tese de Doutorado. São Paulo: Pontifícia Universidade Católica de São Paulo.

Oliveira, P. C. (2003). O processo de aprender noções de probabilidades e suas relações no cotidiano das series iniciais do Ensino Fundamental: uma história de parceria. Campinas: Tese de Doutorado, Universidade Estadual de Campinas.

Rossini, R. (2006). Saberes docentes sobre o tema Função: uma investigação das praxeologias. Tese de Doutorado. São Paulo: Pontifícia Universidade Católica de São Paulo.

Silva, S. A. F. (2009). Aprendizagens de professores num grupo de estudos sobre matemática nas séries iniciais. Tese de Doutorado. Vitória: Universidade Federal do Espírito Santos.

Teixeira, P. J. M. (2012). Um estudo sobre os conhecimentos necessários ao professor de Matemática para a exploração de problemas de contagem no Ensino Fundamental. Tese de Doutorado. São Paulo: Universidade Bandeirante de São Paulo.

Zulatto, R. B. A. (2007). A natureza da aprendizagem Matemática em um ambiente online de formação continuada de professores. Tese de Doutorado. Rio Claro: Universidade Estadual Paulista Campus Rio Claro. 